\title{
Postmodern Zamanın Beklentisi: Bilge Liderlik
}

\author{
Mehmet Ali TAŞ ${ }^{1 *}$, Ali Murat ALPARSLAN ${ }^{2}$
}

Geliş Tarihi/Received: 10.04 .2020

Kabul Tarihi/Accepted: 22.04.2020

Derleme Makalesi / Review Article

\section{ÖZET}

İnsanların ve örgütlerin geleceklerine sahip çıkmaları, kendilerinde bir anlam bulmaları ve varlık sahası içinde kendilerine ihtiyaç duyulan alanı keşfetmeleri ile mümkündür. Karmaşıklaşan ve çok hızlı değişen dünyayı, insanlığı ve insanları doğru anlamak ve anlamlandırmak çok değerli olmakla birlikte, bunun için akıl hocalarına, deneyimli ve derin bakış açılarına daha çok ihtiyaç duyulmaktadır. Belirsizlik ve kaos ortamında doğru kararlar vermek ve öngörülemeyeni tahmin etmek için bilgilenme, deneyimlenme ve derinleşme sayesinde oluşan "ruhsal-sezgi zekanın” kullanılması elzem haline gelmiştir. Bu noktada sadece mevcut verilerle hareket etmeyen değerlerini dayanak kılan ve sezgilerini kullanan bilge liderlerin öneminin arttığı söylenebilir. Bu bağlamda çalışma; bilgeliğin liderlikle ilişkisi, bilge liderliği ve boyutları, bilge liderlerin davranışları ve bu davranışların örgüte olan katkısını geniş bir çerçevede incelemeyi amaçlamıştır.

Anahtar kelimeler: Bilgelik, Liderlik, Bilge Liderlik.

\section{The Expectation Of Postmodern Time: Wise Leadership}

\begin{abstract}
It is possible for people and organizations to take care of their future, find meaning in themselves and discover the area they need in the field of existence. Although it is very valuable to understand and make sense of the complex and rapidly changing world, humanity and people, it is more needed for mentors, experienced and deep perspectives. It has become essential to use "spiritual-intuitive intelligence" created by knowledge, experience and deepening to make

\footnotetext{
1 Arş. Gör., Burdur Mehmet Akif Ersoy Üniversitesi, İktisadi ve İdari Bilimler Fakültesi, Sağlık Yönetimi Bölümü

* Sorumlu yazar/Corresponding author

E-mail/e-ileti: matas@mehmetakif.edu.tr

${ }^{2}$ Doç Dr., Burdur Mehmet Akif Ersoy Üniversitesi, İktisadi ve İdari Bilimler Fakültesi, İşletme Bölümü
} 
the right decisions in the uncertainty and chaos environment and to predict the unpredictable. At this point, it can be said that the importance of wise leaders, who base their values that do not act only with the available data and use their intuition, has increased. In this context, this study aims to examine the relationship of wisdom with leadership, wise leadership and its dimensions, the behavior of wise leaders and the contribution of these behaviors to the organization.

Keywords: Wisdom, Leadership, Wise Leadership.

\section{GíRiş}

Yeni Dünya artık sorunların tümüyle akılcı -yani tıpkı matematik gibi- çözüm önerileri üretilebilen, bu çözümlerin sonuç ürettiği bir zamanda değildir. Bu yüzden örgütsel bağlamda liderlere düşen sorumluluklar da başkalaşmaktadır. Artık karar verme süreçlerinde büyük ölçüde rasyonalite esaslı olunamayabilir. Rasyonel bakışın yanında, öznel yorumların, sezgisel öngörülerin, psikolojik unsurların daha da ötesinde ruhsal dokunuşların gerekli olduğu düşünülmektedir. Bilgece görmek, düşünmek ve davranmak; yalnızca rasyonel bir karar ile oluşabilecek sonuçlardan daha özgün ve etkili olabilmektedir. Belki bu etki kısa vadede zahir olarak görünmeyecek, ama uzun vadeli denge oluşturmak adına bir temel teşkil edecektir.

Liderler artık daha mutsuz, çokça hayal kırıklığına uğramış, haklarından yoksun kalmış veya daha da kötüsü ilgisiz, kayıtsız ve duygusuz takipçileriyle işler başarmak zorunda kalmıştır. İnsanların birçoğu yaptıkları işe anlam yüklememekte, kendilerine dair şahsı manevi bakışı azalttıkları gibi işin de şahsı manevisini düşünmemektedir. Anlamsız buldukları işi yapan çalışanların örgütleri de ruhunu, yani yaşam enerjisini, uzun dönemli hayallerini ve sürekliliği yitirmiş durumdadır (Branson, 2009: 162). İfade edilen, yazılan-çizilen birçok liderlik modelinin işlevsiz olduğunu iddia etmek doğru olmamakla birlikte, yeni beklentilerin olduğunu kabul etmek gerekir. Bilinen motivasyon unsurları ile, bilinen liderlik karakteristikleri ile beklenen etkinin oluşturulup oluşturulamayacağı tartışmalıdır. Konu hakkında üretilen bilgi niceliği giderek artsa da liderliğin ne/nasıl olması gerektiğine dair kafa karışıklığı ve karmaşıklık da artmıştır.

$\mathrm{Bu}$ literatür ile birlikte artan diğer unsurlar ise etik olma, aşkın olma, bilge olma gibi bütüncül ve daha derin unsurlardır (Courtney, 2001). Kişinin hem kendisini hem de diğerlerinin iyiliği arasında denge kurması olarak tanımlanan bilgelik ortak beklenti konumuna gelmektedir (Baltes ve Staudinger, 2000; Sternberg, 1998). Bilge bir kişi, belirsizlik içinde nasıl hareket edileceğini, krizlerin ve ikilemlerin istisnai bir şekilde nasıl çözüleceğini ve kişilerarası 
ilişkilerde özgün ve birleştirici bir şekilde hareket etmek için bilişsel ve duyuşsal unsurları nasıl kullanacağını bilen kişidir (Achenbaum ve Orwell, 1991). Günümüz zamanını tanımlayan bu şartlarda liderlik pozisyonlarında bilgelik niteliklerine daha çok ihtiyaç duyulduğu düşünülmekedir. Çünkü kısa vadeye odaklanmış ve bu yüzden dayanıklılığı ve sürekliliği yitirmiş insanlar ve kurumlar, bilge liderlerin uzun vadeli düşünen, daha dengeli davranan ve daha fazla öngörü kapasitesi sunan özelliklerine gereksinim duymaktadır (Morse, 1996: 14). $\mathrm{Bu}$ yazı kaybedilen derinliğin, derinliklerde var olan değerlerin gelecek ile irtibatının kurularak daha bütüncül görebilen, kasıtlı ve amaçlı yaklaşım gösterebilen ve bu yaklaşımının altında anlamlı bir ufku barındıran, ufka giden yolu bırakmadan, herkesi bu yola katkı sağlar bir niteliğe dönüştürebilen liderliğin, yani bilge liderliğin gereğine dair bir farkındalık oluşturma niyeti ile hazırlanmıştır. Bilgelik kavramının açıklanması ile başlayan çalışma; bilge liderlik kavramının tanımlanması/sınırlandırılması, bilge liderlerin özelliklerinin ifade edilmesi ile devam etmiş, bilgeliğe dayalı liderlik modelinin ve bilge liderliğin boyutlarının literatür çerçevesinde ortaya konulmaya sonlandırılmıştır.

\section{BİLGELİK NEDİR?}

Bilgelik, aslında bireylerin ulaşmak istediği ve bunun için yaşanması gereken bir ideallik durumu, Maslow'un ifadesi tam/olgun insan hali veya kadim ifade ile insanı kâmil olma veya bu hale yaklaşmadır. Bilgeliğin, yaklaşık olarak 6000 yıl önceki kutsal kitaplarda da, yüksek, önemli ve anlamlı bir amaç olduğu görülmektedir (Buzzell vd., 1998). Sonraki dönemlerde ise, Sokrates, Platon ve Aristoteles, bilgeliğin iki formda tezahür ettiğini ileri sürmüşlerdir. Bunlar pratik akıl üstünlüğü ve daha derinlikli olan felsefi bilgeliktir (Takahashi, 2000). St. Augustine ise insan zekâsını; hem rasyonel bilime (maddi dünya bilgisine), hem de Yaratıcının bilgisine ve anlamına vakıf olmaya yetebilen yani fitratı bilge olmaya uygun bir varlık olarak tanımlamıştır. Ortaçağ döneminden Rönesans'a kadar birçok ilim/bilim adamının ele aldığı bilgelik, insan yaşamının ve yaratılışın amaçlarının yerine getirilmesi olarak düşünülmüştür (Trowbridge ve Ferrari, 2011; Schulenburg, 2017: 9). Y1llarca tartışma konusu olmasına rağmen henüz genel ve herkes tarafından kabul görmüş tek bir tanıma da sahip değildir (Ardelt, 2003; Jeste vd., 2010; Schulenburg, 2017: 9; Livingston, 2012: 23). Bilgelik, akıl yürütme, akılcı süreç ve ahlakın bir araya gelmesiyle, bilme, karar verme ve hareket etmenin dengeli ve bütünleşik bir yolunun oluşturulmasıdır (Rooney ve McKenna, 2008; Livingston, 2012: 20). Uzun erimli bir bakış açısıyla bilginin; etik, değerler, estetik unsurlar içerisinde şekillenmesi, insanı şekillendirmesi, ortak iyiliğe ulaşma felsefesidir (Ford, 2007: 1; 
Livingston, 2012: 22). Literatürün taranması ile elde edilen tanımlardan örnekler Tablo 1'de sunulmuştur.

Tablo 1: Bilgelik tanımları

\begin{tabular}{|c|c|}
\hline Araştırmaci/Filozof & Bilgelik Tanımı \\
\hline Farabi $^{1}$ & Bilgelik (hikmet); üstün ilimdir. Bu ilimle en yüce şeyleri anlamak ve kavramaktır. \\
\hline İbn Miskeveyh ${ }^{1}$ & $\begin{array}{l}\text { Bilgelik (hikmet); aklın kılavuzu ve her şeyin örtük yüzüdür. Varoluşun üzerinde } \\
\text { temellendirildiği kanundur. }\end{array}$ \\
\hline İbn $\operatorname{Arabi}^{1}$ & $\begin{array}{l}\text { Bilgelik (hikmet); varlık âlemindeki sıkı düzeninin sırrını, eşyaların iç yüzünü, özelliklerini, } \\
\text { sebep ve sonuç ilişkilerini bilmek ve buna göre hareket etmektir. }\end{array}$ \\
\hline Seyyid Şerif Cürcani ${ }^{1}$ & $\begin{array}{l}\text { Bilgelik (hikmet); kişinin sahip olduğu gücü oranında eşyanın hakikatlerini araştırmasıdır. } \\
\text { Maddenin ötesinde eşyanın derin bilgisini araştıran, eşyanın hakikatinin bilgisidir. }\end{array}$ \\
\hline İbn Sina ${ }^{1}$ & $\begin{array}{l}\text { Bilgelik (hikmet); kişinin nefisinin beşeri gücü oranında kavramları tasavvur etmesidir. Teorik } \\
\text { ve pratik doğruları onaylaması ve bu sayede olgunlaşmasıdır. Bu nedenle hikmet, nefsi } \\
\text { yetkinlikle alakaladır. İnsan nefsin bilici yönüyle eşyayı doğru şekilde anlamakta ve yapıcı } \\
\text { yönüyle de bedeni doğru şekilde yönetmektedir. }\end{array}$ \\
\hline Gazzali $^{1}$ & $\begin{array}{l}\text { Bilgelik (hikmet); akılla idrak etmektir. Akli ve uhrevi ilimlerin birlikte idrak edilmesi } \\
\text { neticesinde hikmet derinleşmektedir. }\end{array}$ \\
\hline $\begin{array}{l}\text { Mevlâns } \\
\text { Rumîn }^{2}\end{array}$ & $\begin{array}{l}\text { Bilgelik (hikmet); kuranı Kerimin ve Hz. Peygamberin kılavuzluğunda kendinin farkında olmak, } \\
\text { kenidini bilmek, gelişmek ve olgunlaşmaktır. }\end{array}$ \\
\hline Önal $^{3}$ & $\begin{array}{l}\text { Bilgelik (hikmet); olgun akıl ve yüksek bilgi anlamına gelmektedir. En iyi ve doğru ilim } \\
\text { aracılığıyla en iyi şeyin bilinmesidir. Aynı zamanda insanın bilmesi ve kavraması neticesinden } \\
\text { faydalı olana odaklanıp zaralı ve kötü olandan kaçınmasıdır. Bu nedenle bilgelik şuurlu bir } \\
\text { anlayış ve kavrama derinliğidir. }\end{array}$ \\
\hline Robinson ${ }^{4,5}$ & $\begin{array}{l}\text { Üç tarihsel tanım sınıflandırması bulunmaktadır: } \\
\text { Yunan: Entelektüel, ahlaki ve pratik bir hayattır. Gerçek ve güzelliğe uygun olarak yaşanan bir } \\
\text { yaşamdır. } \\
\text { Hıristiyan: İlahi ve mutlak gerçek peşinde koşarak yaşanan bir hayattır. } \\
\text { Çağdaş: Maddeyi düzenleyen yasaların bilimsel bir anlayışı ve kavrayışıdır. }\end{array}$ \\
\hline $\begin{array}{l}\text { Csikszentmihalyi ve } \\
\text { Rathunde }^{4,5}\end{array}$ & $\begin{array}{l}\text { Bilgelik, bütünsel bir bilişsel süreçtir. Eylemin altında yatan temel bir erdemdir. İyi ve arzu edilen } \\
\text { bir varlık halidir. İyiliği gerçekleştirmek için bireyin davranışlarını yönlendiren erdemleri ifade } \\
\text { etmektedir. İnsana derin ve içten haz ve mutluluk verir. }\end{array}$ \\
\hline Baltes ve Smith ${ }^{4,5}$ & $\begin{array}{l}\text { Bilgelik, temel yaşam pragmatiği alanında uzmanlıktır. Yaşam konuları hakkında zengin bir } \\
\text { olgusal bilgidir. Yaşam problemleri hakkında zengin prosedür bilgisidir. Farklı yaşam } \\
\text { bağlamları, değerleri, öncelikleri veya hayatın öngörülemezliği hakkında bilgidir. }\end{array}$ \\
\hline Sternberg ${ }^{4,5}$ & $\begin{array}{l}\text { Bilgelik, bilişsel bir üslup içinde sükûnettir. Birinin her şeyi bilmediğini bilmesi ve bildiği ölçüde } \\
\text { gerçeği aramasıdır. }\end{array}$ \\
\hline $\begin{array}{l}\text { Orwoll ve } \\
\text { Perlmutter }\end{array}$ & $\begin{array}{l}\text { Bilgelik, çok boyutlu bir denge veya bilişin sosyal ilgilerle bütünleşmesidir. Bilişsel becerilerle } \\
\text { birlikte ileri kişilik gelişimi, bilgeliğin özüdür. }\end{array}$ \\
\hline Meacham $^{4,5}$ & $\begin{array}{l}\text { Bilgelik bilmenin yanılma payına dair bir farkındalıktır. Bilme ve şüphe etme arasındaki denge } \\
\text { için bir çabadır. Yaş açıkça bir bilgelik bileşeni değildir. }\end{array}$ \\
\hline $\begin{array}{l}\text { Kitchener ve } \\
\text { Brenner }^{4,5}\end{array}$ & $\begin{array}{l}\text { Bilgelik, bilgi sınırlamasının; sorunların eksik tanımlanmasına, çözümünün etkilenmesine, } \\
\text { kararların verilişine ve karar yansımalarının özelliklerine ilişkin farkında olmayı sağlayan } \\
\text { entellektüel bir yetenektir. }\end{array}$ \\
\hline Arlin ${ }^{4,5}$ & $\begin{array}{l}\text { Bilgelik, probleme çözüm bulma yeteneği ile yakından ilişkilidir. Temel bir bilişsel düşünme ve } \\
\text { yargı sürecidir. }\end{array}$ \\
\hline Kramer $^{4,5}$ & $\begin{array}{l}\text { Bilgelik, göreceli ve diyalektik düşünme, etki ve yansıma biçimlerinin organizmik } \\
\text { bütünleşmesidir. İlişkiler içinde geliştirilen gerçeklik üzerine bir bakış açısıdır. }\end{array}$ \\
\hline Birren ve Fisher ${ }^{4,5}$ & $\begin{array}{l}\text { Bilgelik, hayatın görevleri ve problemlerine yanıt olarak insan yeteneklerinin duygusal, gayret } \\
\text { ve bilişsel yönlerinin bütünleşmesidir. Bilgelik, yoğun duygu ve objektiflik, eylem ve eylemsizlik } \\
\text { ile bilgi ve kuşkuların karşıt değerleri arasındaki dengedir. Tecrübe ve dolayısıyla yaş ile artma } \\
\text { eğilimi gösterir. Ancak sadece yaşla beraber kazanılan bir şey değildir. }\end{array}$ \\
\hline Moberg $^{6}$ & $\begin{array}{l}\text { "Ahlaki açıdan mükemmel tepkilere karşı ya da zorlayıcı özelliklerin ortaya çıkmasında akıllıca } \\
\text { bir eğilim” olarak tanımlamıştır. Bu bilgelik tanımı zihinsel keskinliği, ahlaki mükemmelliği ve } \\
\text { durumsal değişkenlerin farkındalığını içermektedir. }\end{array}$ \\
\hline
\end{tabular}

Kaynak: ${ }^{1}$ Altıparmak, 2003; ${ }^{2}$ Kaygısız, 2013; ${ }^{3}$ Önal, 2007; ${ }^{4}$ Sternberg, 1990; ${ }^{5}$ Birren ve Svensson, 2005; ${ }^{6}$ Moberg, 2007. 
Tanımlardan da bellidir ki bilgelik; kişinin bilişsel yeteneğini geliştirerek bilgi birikimi ve bu bilgiyi öz-yansıtma yoluyla kullanmak için gerekli becerileri geliştirmesi olarak ifade edilmektedir. Bilgeliği elde etmenin ikinci yöntemi de kişinin Yaratıcıya olan inancına dayanmaktadır. Yunan düşünürleri, akıl ve analitik yaklaşımına odaklanırken duygularını ve sezgilerini de vurguluyorlardı. Sokrates, Platon ve Aristo gibi Yunan filozofları bu erdem ile ilgili çok konuşmuşlardır. Onların bilgelik tanımına göre, bilge bir insanın geniş bir bilgi tabanına sahip olması, sınırlarının farkında olması, bu bilgiyi başkalarına öğretmesi ve insan hayatının evrensel sorularını kavraması beklenmektedir. Bununla birlikte, bilgeliğin elde edilmesi yalnızca Yaratanın elinde olan bir bilgi arayışını ima etmektedir (Takahashi, 2000: 221; Pierre, 2016: 39).

Diğer taraftan Doğu insanlarının; sadece bilginin değil, aynı zamanda sağduyululuğu da pratik ve duygusal bir durumda kullanılmalarını gerektiren gizli bir karakteristiğe sahip olmaları, bilge olma eğiliminde olduklarını göstermektedir. Bu durum hem analitik yetenekleri hem de insan bilincinin çoklu yönlerini bütünleştirmektedir (Takahashi ve Bordia, 2000: 4-7). Nitekim Japonya, Hindistan, Kuzey Amerika ve Avustralya'da Takahashi ve Bordia (2000, s.4) tarafından yapılan kültürlerarası bir çalışmada, Doğu halkının Batılı muadillerinden daha bilge olma olasılığını ortaya koymuşlardır (Pierre, 2016: 40). Doğu gelenekleri, bilgelik odağını fiziksel dünyadan, doğal dünya ile İlahi güç arasındaki ilişkiyi aydınlanmış bir anlayışa dönüştürmüştür. Asya'ya ait bilgelik literatürü zengin olsa da Batı'daki ampirik bilimle beslenen psikolojiyi bir çalışma alanı olarak fazla etkileyememiştir (Birren ve Svensson, 2005: 9).

Bilgeliğin iyi yaşamak için gerekli bir yetenek olduğu ileri sürülmektedir. İnsanın kendisini tanıması, dünyayı tanınması ve hem kendi hem de başkalarının iyiliği için iyi seçimlerin yapması şeklinde ifade edilmektedir (Branson, 2009: 15). Ki bugünün liderlerin öngörülebilir bir gelecek için bunları yapabilmesi gerekmektedir. Bilgelik kişinin inançlarının, değerlerinin, bilgisinin, yeteneklerinin ve becerilerinin uygulanmasıyla ortaya çıan bir olgudur (Meacham, 1990: 209). Bilge kişiden davranışlar şu beklenmektedir (Branson, 2009: 15).

1. Bilge insanlar hayatı iyi okurlar.

2. Bilge insanlar sahip oldukları anlayışlarını, tercih ve seçimlerine ustaca uygularlar.

3. Bilge insanlar dürüstlükle ve özenle hareket ederler.

Bireylerin, bilgelik düzeyine sahip olduğunu söyleyebilmek için sosyal düzeyde de bazı özelliklere sahip olmaları gerektiğini ileri sürülmektedir. Başkalarının duygularını anlamak ve farkında olmak, öz farkındalığa sahip olmak ve bunu yansıtabilmek, sahip olunan bilginin sınırlarının farkında olmak ve belirsizliği başarılı bir şekilde yönetebilmek (Jeste vd., 2010: 
669; Fairholm, 2004: 581). Bilgelik insanın mükemmeliyetinin doruk noktası olarak ifade edilerek ahlak ile ilişkilendirilmiştir (Baltes ve Kunzmann, 2003: 293). Herhangi bir durumda doğru kararı ve davranışın yargılanması olarak ifade edilmektedir. Bilgelik insan hayatını etkileyen, belirsiz durumlarda kullanılan uzmanlık bilgisi ve doğru yargıdan oluşmaktadır. Ayrıca insan duygularının ve değerlerinin önemsendiği bir anlayışı mümkün kılmaktadır. Diğer yandan örgütlerdeki yöneticiler açısından bilgelik irdelendiğinde, başkalarının refahı ve mutluluğu için kendi hazlarından vazgeçmeyi gerekli kılan bir anlayış olduğu görülmektedir (Govindji, 2015: 22). Bilge insanlar; iyi bir yaşam için akıl ve erdemin kemalatını esas alarak, yaşamın anlamını kavramış ve hem kişisel hem ortak iyilik arasında mükemmel bir denge kurmak için çabalamaktadır (Baltes ve Kunzmann, 2003: 292).

\section{BÍLGE LIDERLİK KAVRAMI}

Örgüt içerisinde etkin liderlik için bilgeliğin gerekli olduğu açıkça belirtilmektedir. Hatta bilgelik bir liderin sahip olabileceği en önemli ve en nadir erdemlerden biri olarak gösterilmektedir (Schulenburg, 2017: 43). Belli bir durumda neyin en iyisi/doğrusu olduğuna karar vermek bilgelik gerektirir. Bu bakış bazen kesin olarak doğru olandan ziyade belirli bir durumda en uygun, durumla en uyumlu olana karar vermeyi gerektirmektedir (Livingston, 2012: 85).

Bilge bir lider, kendi çıkarları, kendini geliştirme ya da kendini beğenme ile motive olmaz. İçselleştirilmiş bir ahlaki zorunluluk olarak başkalarına yardım etmek için derin bir istekle motive olmaktadır. Özgünlük ve ahlaki bütünlük, bilge liderlerin karakteri için temel oluşturmaktadır. Bahsedildiği üzere bireysel özgünlüğe sahiptirler. Otantik yanları bulunmaktadır. Bir başkasının lider olma yöntemini kopyalaması beklenmez. Kendileri için en iyi liderlik tarzını bulmaları ve önderlik ettikleri kişilere en iyi yardımı sunmaları beklenmektedir. Sözler ve eylemler arasında tutarlılık şarttır. Önem verilen değerler ve eylemler birbirini desteklemesi gerekmektedir (Branson, 2009: 32).

McKenna vd. (2009), örgütsel bir bağlamda liderler arasında özellikle bilgelik tezahürü ile ilgili önemli bir çerçeve ortaya koymaktadır. Bu çerçeve şimdiye kadar anlatılan örgütsel bilgelik özelliklerinin çoğunu barındırmaktadır. İlk olarak, bilge liderlerin gerçekleri ve tümdengelim açıklamalarını oluşturmak için kritik "gözlemler" yapmaları gerekir. Bilgi toplarken ve karar alırken entelektüel, duyuşsal, motivasyon ve sezgisel yönlerini kullanmaktadırlar. Bu da onların örgütlerdeki belirsizliği güçlü bir şekilde yönetmelerini sağlamaktadır (Boal ve Hooijberg, 2001). Bunun yanında yine McKenna vd. (2009), bilge liderin pratik yanının da güçlü olduğunu, eylemleri pratik olarak günlük çalışmalara 
indirgeyebildiğini, "indirgeyebilme özelliğinin” önemli/ayırt edici bir özellik olduğunu iddia etmektedir. Hayal ile pratik arasındaki iletişimin bilge liderlik için gerekli olduğunu belirtmektedirler (Govindji, 2015: 26).

\subsection{Bilge Liderin Özellikleri}

Nonaka ve Takeuchi (2011), bilge liderlerin altı temel yeteneğini önermişlerdir.

İyiliği Muhakeme Etme: Bilge liderler, sahip oldukları değerlere ve ahlaka dayanarak neyin iyi olduğunu ayırt edebilmekte, her zaman bu farkındalık üzerinde hareket etmektedirler. Bilge liderlerin bilgi, tecrübe ve anlayışlarını muhakemelerine en iyi şekilde kaynak olarak kullanabilme becerisine sahip oldukları iddia edilmektedir (Govindji, 2015: 54). Nonaka ve Takeuchi (2011), bilge liderlerin, muhakeme gerektiren ayrıntılarda yeni bilgileri analiz etmede sezgisel bilgiyi kullandıklarını belirtmektedirler. Doğru kararları vermek için bir durumun özünü derinlemesine kavramanın önemi vurgulanmaktadır. Bir organizasyonda bilge liderlerin ilk önerilen özelliği, iyi muhakemede bulunmak için açık ve zımni bilgiyi etkin bir şekilde birleştirebilmesidir (Govindji, 2015: 55).

Özü Kavrama: Bir karar vermeden önce, bilge liderler bir durumu anlayabilir, gelecekteki sonuçlarını öngörebilir, esası gözeterek vizyonlarını gerçekleştirecek doğru eylem hakkında hızlıca karar verebilmektedirler (Govindji, 2015: 26).

Paylaşılan Bir İçerik Oluşturma: Üst düzey yöneticilerin ve çalışanların etkileşimleri yoluyla yeni anlamlar inşa etmeleri için sürekli gayrı resmi ve resmi paylaşılan düzlemler yaratmaktadırlar. Örneğin, çalışanların ve liderlerin birbirlerinden öğrenmesi için firsatlar yaratarak paylaşım kültürü inşa etmektedirler. Bilginin paylaşılması; etkileşimler yoluyla yeni ilişkiler kurulması, güçlü ve anlamlı çözümlerin birlikte oluşturulması, başkalarının bakış açılarını ve ihtiyaçlarını anlamak için gereklidir.

Özü İletme: Gerçek deneyimlerinin özünü, bireyler ve gruplar için anlaşılabilir kılmak için metaforları ve hikâyeleri nasıl kullanacaklarını bilirler. Bilge liderlerin, karmaşık mesajları herkesin anlayacağı şekilde iletebildikleri ve farklı bağlamlardan bireylerin mesajlarını sezgisel olarak kavrayabilmeleri için hikâyeler, mecazlar ve figüratif dil gibi yöntemleri kullandıkları bilinmektedir.

Politik Gücü Kullanma: İnsanları bir araya getirme, herkesin bilgisini sentezleme ve ortak bir hedefe ulaşmak için harekete geçirme yetenekleri vardır. Bilge liderler, politik kararlarını başkalarının bakış açılarını ve duygularını anlayarak uygularlar ve diğerleriyle doğru zamanda ilişkiler kurarak doğrudan veya dolaylı etki altında bırakırlar. 
Diğerlerinin Pratik Bilgeliğini Geliştirme: Özellikle ön saflardaki çalışanlara; ustalık ve mentorluk yaparak pratik bilgeliğin gelişimini sağlayabilirler. Teori, bilge liderlerin bilgi ve bilgeliklerini kendi örgütlerinde mümkün olduğunca dağıtarak, çalışanlara öğretme ve çalışanlarla öğrenme gibi etkileşim firsatları oluşturarak düşünme, fikir üretme, amaç ile eylemleri irtibatlandırma gibi zihinsel gelişim ve üretime zemin sağlar. Bu, çalışanların yeni durumlarda daha fazla esneklik kazanmasına ve olağandışı düşünebilmesine olanak sağlar (McKenna vd., 2013; Govindji, 2015: 26).

Belirsizliği Yönetme: Baltes vd. (2002) ve McKenna vd. (2009), bilge bireylerin insan varoluşu (nedeni ve gayeleri) hakkındaki bilginin eksikliğine dair içgörüye sahip olduklarını belirtmektedirler. Kişinin sahip olduğu bu bilgi ve bu bilgi ile güçlenen sezgi, liderlerin kuruluşlardaki belirsizliği güçlü bir şekilde yönetmesini sağlamaktadır. Bilgelik aynı zamanda bireylerin; hayatın tahmin edilemez ve belirsiz doğasını kabul etmesini de içerdiği için gerekli adımları bu doğrultuda atmasını sağlamaktadır (Dey, 2012). Bir organizasyonda bilge liderlerin belirsizliği tanıyarak, kabul ederek, bilgi ve sezgisiyle bu durumu rahatça yönetebilmeleri başat özelliklerinden biridir (Govindji, 2015: 56).

Denge Kurma: Bilge liderler, karar verirken birden fazla perspektifi kullanması muhtemeldir. Korac-Kakabadse vd. (2001), liderler ve takipçiler arasında psikolojik bir kontratın sürdürülmesinin önemini vurgulamış ve bunu etkili bir şekilde yönetebilmek için çoklu perspektifi dikkate alma gereğini vurgulamışlardır. O nedenle bilge liderliğin kişisel, kişilerarası ve dışsal durumlar arasında başarılı bir denge kurmaları gerekmektedir (Govindji, 2015: 56).

Tevazu: Vera ve Rodriguez-Lopez (2004), alçakgönüllülüğün organizasyonlarda stratejik bir değer yarattığını öne sürmektedir. Mütevazı liderlerin, bilgilerinin sınırlarını bilmelerini, kişisel güçlü ve zayıf yönlerini değerlendirmede başarılı oldukları belirtilmektedir. $\mathrm{Bu}$ yüzden yeni paradigmalara açık ve başkalarından öğrenmeye istekli olmaktadırlar. Dolayısıyla ortak hedeflere doğru, başarılı bir işbirliği ile yürüyebilir ve yürütebilirler. Bilge liderlerin önemli bir özelliği de diğerlerinden öğrenebilme yetenekleri aracıllı̆̆ıla alçakgönüllülük göstermeleridir (Govindji, 2015: 56). Hatta buna dair Nonaka ve Takeuchi (2011), bilge liderlerin, alçakgönüllülüğün bir işareti olarak çalışanlardan öğrenme firsatlarını değerlendirdiklerini ileri sürmüşlerdir.

Öz Farkındalık: Avolio vd. (2004: 4), otantik liderleri “kendi ve başkalarının değerleri, bilgisi ve güçlerinin farkında olarak başkaları tarafından nasıl algılandığını ve nasıl davrandığını derinden bilen bireyler” olarak tanımlamıştır. Bu liderilerin; karakteri, güçlü 
yönleri, zayıflıkları ve çevreleriyle ilgili yüksek öz farkındalığa sahip oldukları ileri sürülmektedir. Winter (1991), birinin kendi karakteri konusunda eleştirel bir değerlendirme yapmasının değerli olduğunu, bunun sahip olduğu öz-farkındalığıyla ilgili olduğunu ifade etmektedir.

Ahlâk: Ahlak; liderlik ve bilgelik literatüründe yer alan önemli bir temadır. Otantik ve erdemli liderlik teorileri içsel ahlakı tanımlar ve doğruyu yanlıştan ayırt etmeyi ön planda tutarlar (Avolio ve Gardner, 2005; Walumbwa vd., 2008). Winter (1991), güçlü bir sorumluluk duygusuna sahip liderlerin doğru olanı yapmasını, başkalarıyla ilgili endişelerini ortaya koymasını ve böylece etik liderliğin önemini vurgulaması önerilmektedir. Neyin doğru olduğunu ve her durumda ne yapılması gerektiğini yargılama kapasitesine ilişkin "ahlaki bilgelik" kavramı vurgulanmaktadır.

\subsection{Bilgeliğe Dayalı Liderlik Modeli}

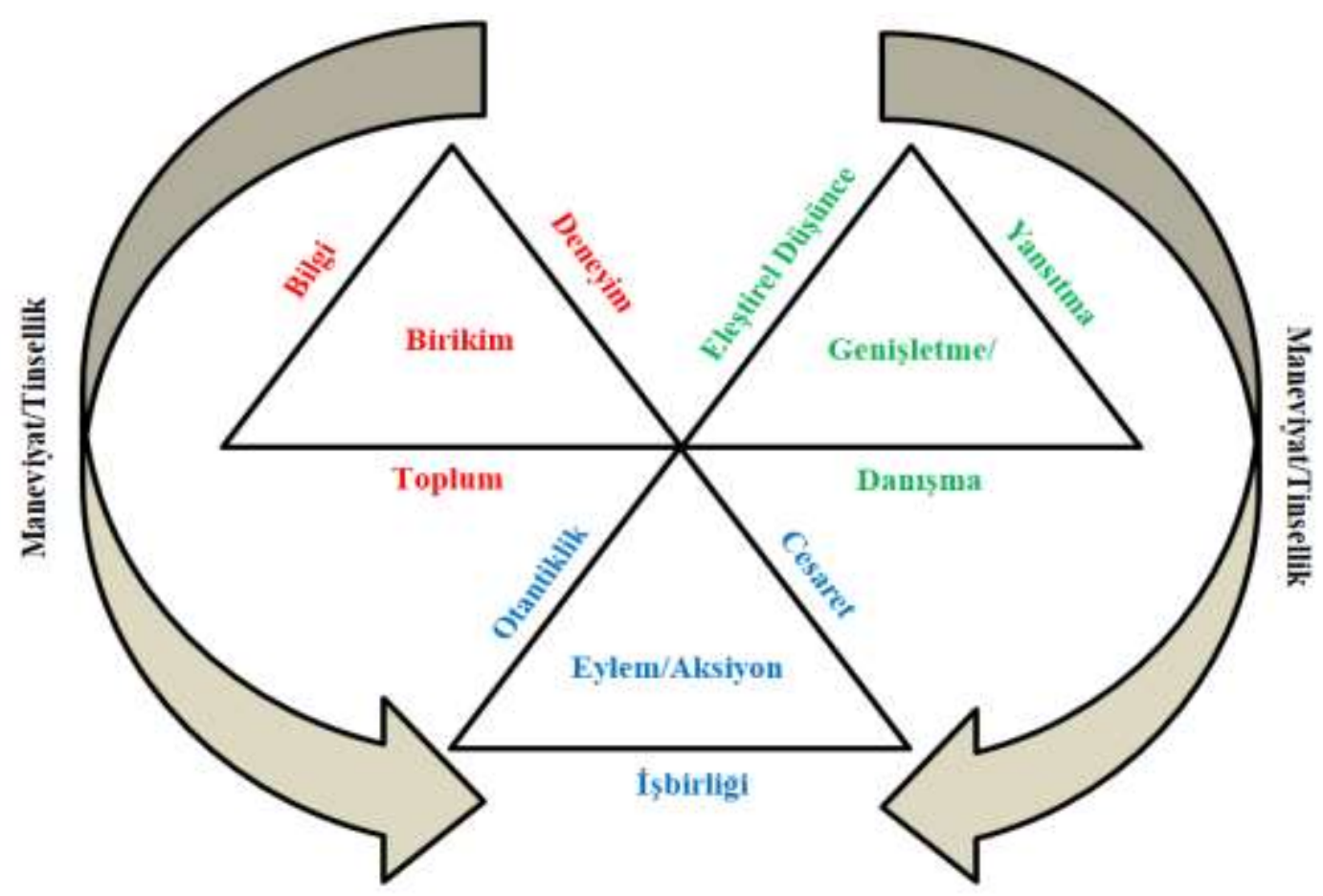

Şekil 1. Bilgeliğe dayalı liderlik modeli

$\mathrm{Bu}$ modelin önemli bir yönü, bireyin bilişsel, duyuşsal ve uyum süreçlerinin entegrasyonu olarak bilgeliği ortaya koymasıdır. Başka bir deyişle, bilgelik; düşünme, hissetme ve hareket etmenin birleşimidir. Ek olarak, model hem ayrı hem de dinamik olarak birbiriyle bağlantılı üç ayrı ilerleme (birikim, genişleme ve eylem) içermektedir. Bu üç süreç birbirine 
bağlı bir şekilde ilerlemektedir. Her bir sürecin ilgili yapıları aynı renklerle temsil edilmektedir (Ludden, 2013: 2; Schulenburg, 2017: 32).

\subsubsection{Birikim (Accumulation)}

Şekil 1'de görüldüğü üzere WBLM üç aşamaya sahiptir. Bilgeliğin birikim aşamas1, bilginin edinilmesi yoluyla, çeşitli deneyimlerin peşinde koşarak ve insanların topluluklarına dâhil olma yoluyla yeni fikirlere açık kalmak suretiyle sürekli öğrenme sürecini içermektedir (Ludden, 2013; Schulenburg, 2017: 33).

Bilgi (Knowledge): Bilgi, bilgelik literatürünün merkezi bir ilkesi olmaya devam etmektedir. Fakat her bilginin bilgeliğin kazanılması için eşit derecede yararlı olduğu söylenemez. Bilgi bilgeliğin merkezi olsa da, bilgeliğin özü, bilinenin içinde değil, bu bilginin nasıl kullanıldığına dayandığıdır (Meacham, 1990: 188). Berlin Grubu bu ayrımı bilgelikle ilgili bilgi tanımında, "durumun özü hakkındaki bilgi, değerlendirme, bir yaşamı planlama, yönetme ve anlama yolları ve araçları" olarak adlandırmaktadır (Baltes ve Staudinger, 2000: 124). Bilge liderler, hem resmi hem de gayri resmi olarak bilgi toplarlar ve operasyonel bilgi ile dengelerler (Schulenburg, 2017: 33).

Deneyim (Experience): Bilgelik, deneyim ve öğrenme ile şekillenmektedir (Meeks ve Jeste, 2009). Kolb (1984), bilginin, kişinin deneyimlerinde oluşturulduğunu ve test edilerek pekiştirildiğini ifade etmektedir. Merriam vd. (2007), insanların deneyimlerden çeşitli şekillerde öğrendiklerini ifade etmektedir. Somutlaşmış, simüle edilmiş ya da geçmiş deneyimler öğrenmenin en zengin kaynaklarıdır (Knowles vd., 2005). Deneyimlerden aktif olarak öğrenme, bilgelik gelişimi için çok önemlidir. Akıl ile deneyim arasındaki bağlantı, bilgeliğin yaşla birlikte elde edildiği genel inancını da açıklamaktadır (Meacham, 1990: 197). Bilgelik, yaşam krizlerinin başarılı çözümü ile ilgili deneyimler yoluyla da gelişmektedir (Schulenburg, 2017: 35).

Topluluk (Community): Bilgelik, doğası gereği etik olmalıdır. Bencillik, nefret veya acımasız davranışlar bilgelikle asla bağdaşmamaktadır. O nedenle bilgeliğin temel bir argümanları empati, merhamet, sevgi, fedakârlık ve adalet duygusu gibi olumlu hasletlerdir (Bangen vd., 2013). Nonaka ve Takeuchi (2011), bilgeliği ortak yarar için hareket etme yeteneği olarak tanımlamışlardır. Bilgelik, toplumdan tecrit olarak kazanılamamaktadır. Bangen vd. (2013: 1263), bilgi sahibi olma ve iyi karar verme yeteneklerine sahip olmakla birlikte, olumlu sosyal değerlerle bütünleşme/bütünleştirmenin bilgece olduğunu 
söylemektedir. Bilgelik paylaşma ve toplum nezdinde iyi olmadır (Schulenburg, 2017: 35; Livingstone, 2012: 58-59).

\subsubsection{Genişletme/Büyütme (Amplification)}

WBLM'deki bir sonraki aşama, bilgi birikimi, deneyim ve toplumla etkileşimin güçlendirilmesini içermektedir. Böylece bütün, parçalardan daha büyümüş ve güçlenmiş olacaktır.

Eleştirel Düşünce (Critical Thinking): Zekâ ve elde edilen bilginin, bilgelikte açık bir rolünün olduğu aşikârdır. Fakat bilgi yeterli değildir. Bilgelik; eleştirel düşünmeyi, bunun tartışılan bileşenleri arasında (bilgi, içerik, toplum, etik ve deneyim) intikal kurmayı gerektirir. Howard vd. (2014) eleştirel düşünceyi varsayımları sorgulayan yüksek düzeyli düşünce olarak tanımlamışlardır. Gözlem, deneyim, yansıtma, akıl yürütme veya bunlardan elde edilen bilgilerin aktif veya ustaca kavramsallaştırılması, uygulanması, analiz edilmesi, sentezlenmesi ve/veya değerlendirilmesi için entelektüel olarak disiplinli bir süreç gerektirdiğini ileri sürmektedirler (Schulenburg, 2017: 36). Eleştirel düşüncenin hem inanç hem de eylemleri yönlendirdiğini ifade edilmektedir (Livingstone, 2012: 60).

Yansıtma (Reflection): Örtülü anlayışın eyleme yansımasıdır. Düşüncelerin eyleme dönüşmesini ifade etmektedir. Kendini yansıtma, bilgeliğin bir bileşeni olarak ele alınmakta ve önseziler için gerekli bir koşul olduğu ileri sürülmektedir (Meeks ve Jeste, 2009). Yansıtma bileşeni gelecekteki eylemler için bir temel oluşturmaktadır. Çünkü bireyler; çevrelerini izler, gördüklerini yorumlar ve tepkilerini formüle ederler. O nedenle tüm bireylerin eylemleri bir dereceye kadar bilinçle gerçekleşmektedir (Weick ve Ashford, 2000: 70). Yansıtma aynı zamanda bir öğrenme aracı olması açısından önem arz etmektedir. Bandura (2003), insanların iç çatışmaları çözmek için yansıtma kullanma ve eylemin anlamını aramaya çalışma yeteneğine sahip olduklarını belirtmektedir (Schulenburg, 2017: 37). Trowbridge (2006) bu yansitıc1 düşünceyi bir problemi düşünmek, gerekirse uzun bir süre üzerinde yoğunlaşmak, çok miktarda bilgi almak ve çeşitli şekillerde entegre etmek için bir yetenek şeklinde görmektedir (Livingstone, 2012: 60).

Danışma (Delebration): Ludden (2013) danışmayı; karar vermek ve eyleme geçmek için fikir, düşünce, bilgi ve deneyimleri düşünmek üzere başkalarıyla ilişki kurmak olarak tanımlamıştır. Elbette, bu yolu açık bir iletişim tarzıdır. Açık iletişim, bir organizasyon içinde etik bir iklim oluşturmanın da bir yoludur, güven oluşturmanın ise temelidir (García-Marzá, 2005: 209). Danışma; lider ve takipçiler arasındaki ilişkiyi kurarak bilgeliğin güçlendirilmesine 
de izin vermektedir. Başkalarının ihtiyaçlarına odaklanmak hem dönüşümcü hem de hizmetkâr liderliğin temel ilkesidir (Schulenburg, 2017: 38).

\subsubsection{Eylem (Action)}

Bilge bir kişi, verdiği kararların bilgece olmak zorunda olduğunun bilincindedir (Ludden, 2013). Modeldeki eylem bileşeni, onu salt düşünce veya spekülasyondan ayıran bir bilgelik yapısını temsil etmektedir. Eylem ve alt bileşenlerinin açıklaması aşağıdadır (Schulenburg, 2017: 38).

Otantik Olma (Authenticity): Otantik bir insanın, özellikle bir liderin kendi sesini bulması ve bu sesin tutarlı olması gerekmektedir. Bu özgün sesi bulmadaki ilk adım, kişisel değerleri ve inançları uzlaştırmak ile gerçekleşir (Kouzes ve Posner, 2007: 49). Otantik liderler kişisel değerlere uygun olarak hareket ederler. Farklı bakış açılarını teşvik ederek ve takipçilerle işbirlikçi ağları kurarak, güven kazanmaktadırlar (Livingstone, 2012: 63). Yüksek düzeyde özgünlük sergileme cesaretine sahiptirler. Kim olduklarını, neye inandıklarını ve neye değer verdiklerini bilmektedirler. Başkalrı için kendi değer ve amaçlarından ödün vermek istemezler. Diğerleriyle şeffaf bir şekilde etkileşimde bulunurken bu değerler ve inançlar üzerinde hareket etmektedirler (Avolio vd., 2004).

Cesaret (Courage): Bilgelik ahlaki cesareti gerektirmektedir. Ahlaki cesaret, bir kişiyi, risklere rağmen doğru olanı yapmaya zorlar (Chapa ve Stringer, 2013). Elbette bu cesaretin öncülü, liderin neyin doğru olduğunu bilmesi ve buna ne denli inanması ile alakalıdır. Cesur bir lider, büyük resmi anlama ve uzun vadeli hedefler için fedakârlık etme isteğini içeren temel değerlere bağlıdır. Hays (2007: 79) örgütsel bilgeliğin bazen iş mantığına karşı koyma cesaretini gerektirdiğini belirtmektedir. Ludden (2013), cesareti; muhalefet veya başarısızlık şansı ne olursa olsun doğru olanı yapma gücü olarak ifade etmektedir (Schulenburg, 2017: 40). Cesaret; tehlike, belirsizlik, risk ve sıkıntı karşısında hedeflere ulaşma iradesini içeren duygusal güçleri beraberinde getirmektedir (Livingston, 2012: 66).

İşbirliği (Collaboration): Kuruluşlar, ortak bir hedefe doğru birlikte çalışan insanlara ihtiyaç duyar. $\mathrm{Bu}$ işbirliğini kolaylaştırmak için de liderlere düşen önemli görevler bulunmaktadır. Ludden (2013), işbirliği; bir kişinin, başkalarıyla aynı işi gerçekleştirirken organizasyonun amacına ulaşmak için birlikte hareket etmesi olarak tanımlamaktadır. İşbirliğinin amacı, bir bireyin gereksinimlerinin ötesine uzanan ortak vizyon ve stratejilerin oluşturulmasıdır (Chrislip ve Larson, 1994). İşbirliği; üyelerin birbirleriyle iletişsim kurmasını, tüm perspektifleri dinlemesini, ekibin tek bir sese dönüşmesini sağlamaktadır (Livingston, 2012: 69). 


\subsubsection{Maneviyat (Spirituality)}

Maneviyat bilge liderlik kavramını çevreleyerek kuşatmaktadır. Bir liderin ruhaniyeti, dünya görüşü için mihenk taşı olarak görülmektedir. Hakikatin kesin olmadığı durumlarda bir karar verilmesi gerektiğinde inanç, denklemin bir parçası olarak karara kaynaklık eder. İnanç, illaki bir Tanrı anlamına gelmemektedir. Bu inanç ve maneviyat, bilge bir liderin zor bir ahlaki standarda uymasını sağlayan bir düşünce kaynağıdır, çıkış noktasıdır. Bir liderin dünya görüşü için temel oluşturan maneviyat; zor, tehlikeli, popüler olmayan bir karar vermek için ahlaki cesaret vermektedir. Ludden (2013), maneviyat1; daha yüksek bir güçten bilgelik istemek ve kişinin bilgelik kazanmasıyla planlı olarak sürekli ruhsal gelişimi ifade etmektedir (Schulenburg, 2017: 41-42; Livingston, 2012: 71).

\subsection{Bilge Liderliğin Boyutları}

Bilge liderlik boyutlarıyla ilgili yapılan ilk kapsamlı çalışmanın, Reena Govindji (2014) tarafından hazırlanan doktora tezi ile gerçekleştiği tespit edilmiştir. Govindji bu çalışmasında; bilgelik modelleri, bilge liderlik teorileri ve mevcut bilgelik ölçekleri ile ilgili literatürü gözden geçirmiş ve bilgelik kavramının, mevcut liderlik modellerine hangi alanlarda nasıl değer kattığını değerlendirmiştir. Bu aşamadan sonra bilge bir liderlik ölçeğini geliştirme ihtiyacının olduğunu da vurgulamaktadır. Bilgelik ve liderlik paradigmalarının gözden geçirilmesine dayanarak, örgütlerde bilge liderliğin özelliklerini tanımlamak için karma yöntemler ile hazırlanmış üç çalışmaya dayanan bir araştırma tasarlamıştır. Yapılan kritik olay görüşmelerinden sonra; Güçlü Etik Kod, Güçlü Muhakeme, Olumlu Sonuçları Optimize Etme, Belirsizliği Yönetme, Güçlü Miras, Amaçla Liderlik Etme, İnsanlık, Alçakgönüllülük ve Öz Farkındalık boyutlarından oluşan dokuz boyut belirlenmiştir. Bu boyutlar da açıklamalarıyla birlikte tablo 2'de sunulmuştur. 
Tablo 2. Bilge liderliğin boyutları

\begin{tabular}{|c|c|}
\hline \multicolumn{2}{|c|}{ Bilge Liderlik Boyutlarının Tanımları } \\
\hline $\begin{array}{l}\text { Güçlü } \\
\text { Etik } \\
\text { Kurallar }\end{array}$ & $\begin{array}{l}\text { Karar ne kadar zor olursa olsun, bilge lider her zaman doğru bildiğini yaparak } \\
\text { yönlendirir ve bunu yapmak için gerekli olan cesarete sahiptir. Hiçbir şekilde ahlaki } \\
\text { değerlerine ters düşmez. Sahip oldukları vizyon, stratejiler ve yaklaşımları hakkındaki } \\
\text { görüşlerinde ve eylemlerinde tutarlılık gösterirler. Bu tutarlılık kendilerine duyulan } \\
\text { saygının ana kaynağını ve gücünü oluşturmaktadır. }\end{array}$ \\
\hline $\begin{array}{l}\text { Güçlü } \\
\text { Muhakeme }\end{array}$ & $\begin{array}{l}\text { Bilge liderler, karmaşık bilgileri hızlı bir şekilde analiz etme ve filtreleme becerisine } \\
\text { sahiptirler. Stratejik kararlar vermek ve buna göre hareket etmek için örtük bilgileri } \\
\text { yönlendirici olur. Deneyimlerinden beslenerek deneyim ederler. }\end{array}$ \\
\hline $\begin{array}{l}\text { Olumlu } \\
\text { Sonuçları } \\
\text { Optimize Etme }\end{array}$ & $\begin{array}{l}\text { Karmaşık ortamlarına ve baskılana rağmen, bilge liderler kendileri, paydaşları ve dış } \\
\text { koşullar için sonuçları hem dengeleyen hem optimize eden kararlar almaktadırlar. }\end{array}$ \\
\hline $\begin{array}{l}\text { Belirsizliği } \\
\text { Yönetme }\end{array}$ & $\begin{array}{l}\text { Bilge liderler belirsizliği tanır ve rahatça yönetirler. Farklı ve geniş bakış açısıyla } \\
\text { çözüm odaklı odaklanırlar ve zorluk ne olursa olsun odaklanmış kalma gerekliliğini } \\
\text { kabul ederler. }\end{array}$ \\
\hline Güçlü Miras & $\begin{array}{l}\text { Güçlü, uzun ömürlü ve olumlu bir etki yaratmak, görev ne kadar küçük olursa olsun } \\
\text { bilge liderler için önemlidir. Bilge liderler sahip oldukları vizyon ve aldıkları kararlar } \\
\text { ile, geiştirdikleri iç ve dış paydaşlarla ilişkiler ile, karmaşık sorunları çözme biçimleri } \\
\text { aracılığıyla örgütleri için güçlü bir miras oluştururlar. }\end{array}$ \\
\hline $\begin{array}{l}\text { Amaca } \\
\text { Yön Verme }\end{array}$ & $\begin{array}{l}\text { Bilge liderler, yaptıkları her şeyin altında yatan derin bir amaç anlayışına sahiptir. Bilge } \\
\text { liderler için bu amaç, menfaat sahiplerini olumlu yönde etkilemeye odaklanarak daha } \\
\text { büyük iyiliğe katkıda bulunmakla ilgilidir. Amaç ile iletişim kurarlar ve kuruluşlarını } \\
\text { iyiye ulaştırmak için bir "araç" olarak kullanırlar. Her eylemde amaç ile eylem arasında } \\
\text { intikal kurarlar. }\end{array}$ \\
\hline İnsanlık & $\begin{array}{l}\text { Bilge liderler, insanlara karşı koşulsuz bir bakış açısı ile insanlığı önemserler. } \\
\text { Başkalarının saygınlığını korur, ilgi alanlarına ve perspektiflerine saygı gösterir ve } \\
\text { eylemlerinin diğer insanların refahı üzerindeki etkisinin sorumluluğunu üstlenirler. }\end{array}$ \\
\hline Alçakgönüllülük & $\begin{array}{l}\text { Bilge liderler ego merkezli değildirler ama aynı zamanda uyuşuk ya da çekingen de } \\
\text { değildirler. Genellikle karakterleri sağlam ve tutarlıdır. Ancak bilge liderler katkılarını } \\
\text { daima daha büyük bir resmin parçası olarak görürler. Her zaman başkalarından } \\
\text { öğrenmeye ve hatalarını kabullenmeye isteklidirler. Başkalarına gerektiğinde kredi } \\
\text { verirler. Kendilerini her zaman eksik hissederler. }\end{array}$ \\
\hline Öz-Farkındalık & $\begin{array}{l}\text { Güçlü ve zayıf yönleriyle ilgili güçlü bir farkındalıkları vardır. Kendi zayıflıklarını } \\
\text { telafi etmek için başkalarıyla birlikte çalışmaları esastır. Bilge liderler sergiledikleri } \\
\text { davranışların başkalarına, kuruluşlarına ve dış çevrelerine olan etkilerinin } \\
\text { farkındadırlar. Başkalarından da geri bildirim alarak birden fazla bakış açısına sahip } \\
\text { olmaktadırlar. }\end{array}$ \\
\hline
\end{tabular}

\section{TARTIŞMA VE DEĞERLENDİRME}

Bilgelik, doğru olanı anlamadır. Bu yüzden bilgeliğin, kişisel çıkarların ötesinde olduğu ifade edilmektedir. Bilge kişinin uygulaması başkalarına fayda sağlaması yönündedir. O nedenle bilgeliğin ahlaki davranışı destekleyen en önemli erdem olduğu ileri sürülmektedir (Branson, 2009: 33). Ancak literatür tarandığında çok az araştırmanın bilgelik ile liderlik teorisi özel olarak ilişskilendirdiği görülmektedir. Birkaç çalışma, liderlere bilge olarak bakmıştır (Achenbaum ve Orwell, 1991; Barry ve Elovitz, 1992). 
McKenna ve meslektaşları (2009), liderlerde mükemmel muhakemenin, anlayışın ve karakterin ihtiyaç duyulduğu bir zamanda, çağdaş yönetim veya liderlik söyleminde "bilgelik" kelimesinin nadiren görüldüğünü belirtmiştir. Bilgi, deneyim ve işbirliği yoluyla; eleştirel düşüncenin ve tartışmanın güçlendirilmesi gerektiği ifade edilmektedir. Maneviyat çerçevesinde otantiklik, cesaret ve işbirliği etrafında eylem göstermektir. Bilgeliğe doğru bir eğilim, daha yüksek bir gelişme aşamasına doğru bir harekettir ve ilerlemedir (Baltes, 2004).

Bilgelik, bireysel ve kollektif seviyelerde ideal bir kalkınma olarak ütopik fikirleri oluşturmaktadır (Baltes ve Kunzmann, 2004). Bilgelik, çoğu zaman, insan bilgisinin ve gelişiminin olası bir son hali, olgunluk hali, tam/tüm insan hali olarak düşünülmüş̧ür (Baltes ve Smith, 1990: 90). Daha sonra bilgelik kavramı, lider ve çevre arasındaki etkileşimin anlaşılmasıyla örgütsel bağlamda irdelenmeye başlamış ve en yüksek performansın gerçekleşmesi için ihtiyaç duyulan bir gelişme olarak görülmüştür (Baltes ve Staudinger, 2000: 125). Bununla birlikte, bilgelik insanlık yoluyla işlevsel hale getirildi ve bu nedenle, bilgelik tezahürlerini açıklamaya yönelik araştırma, meşru bir bilimsel çaba şeklinde kabul edilmeye başlandı (Livingston, 2012: 83).

Giderek kaotikleşen, değerlerin yozlaştığı, insanların uzun vadeli ve bütüncül düşünmediği günümüzde ihtiyacımız bilgece bakış, bilgece düşünüş ve bilgece davranıştır. Toplumları bilgece yaşamaya, bilge liderler sevk edebilecektir. Bu yüzden Farabi'nin de ifade ettiği üzere bilge ve erdemli liderlere ihtiyaç vardır. Geçmişi dün ile sentezleyen, günü en doğru okuyan, böylece geleceğe doğru bir istikamette yürüyebilen, gerekirse özgün ama ödün vermeyen ve insanları bu yöne ikna eden, hem duygular hem akıl yoluyla kalpleri mutmain eden sakin ama kararlı, cesur ama tutarlı liderlere ihtiyaç vardır. Yönetimi altında güven duyulan, anlamlı amaçlar koyan ve ömrünü bu amaçlara feda eden, kişisel çıkar ötesinde daha yüce bir bütüne hizmet eden bir bakışa ihtiyaç vardır. Hayatı bulduğu gibi bırakmayan, katkı sağlayan, dağınık kaynakları koyduğu vizyonla, mütevazı ve fedakâr tavrıyla, bütüncül bakışıyla toparlayan, iş birliği yapan liderlere ihtiyaç vardır. Belki liderliğe dair bilgi ve tecrübe birikimi çokça artmıştır. Hatta bilim liderlik olgusunu farklı boyutları ile derinliklerine kadar incelemiştir. Demek istenen odur ki sorun bilgi kısmında değil, bilgelik kısmının eksik kalmasindadir.

Konu ile alaklı gelecek araştırmalardan beklentiler; bilge liderliğin boyutlarının, Türk kültürü açısından yeniden tanımlanması, özellikle kuşak değişimleri 1şığındaki bilge ihtiyacının, bilge özelliklerin yeniden ortaya konmasıdır. Elde edilen bulgular bağlamında bilge liderliğin boyutları karşılaştırılarak, Türk toplumunda hangilerinin daha fazla kabul 
gördüğünün ortaya konulması önem arz etmektedir. Diğer yandan bilge liderlerin de çalışanların tutum ve davranışlarını nasıl şekillendirdiği ve kurumlar ve gruplar üzerinde nasıl bir etkiye sahip olduklarını belirlemek için görgül çalışmalara ihtiyaç vardır.

\section{KAYNAKÇA}

Achenbaum, W. A. \& Orwell, L. (1991). Becoming Wise: A Psychogerontological Interpretation of the Book of Job. International Journal of Aging and Human Development, 32, (21-39).

Altıparmak, Ö. F. (2003). Hikmet ve Felsefe İlişkisi. Harran Üniversitesi İlahiyat Fakültesi Dergisi, 11(11), 86-118.

Ardelt, M. (2003). Empirical Assessment of a Three-dimensional Wisdom Scale. Research on Aging, 25(3), 275-324.

Avolio, B. J. \& Gardner, W. L. (2005). Authentic Leadership Development: Getting to the Root of Positive Forms of Leadership. The Leadership Quarterly, 16, 315-338.

Avolio, B. J., Gardner, W. L., Walumbwa, F. O., Luthans, F. \& May, D. R. (2004). Unlocking the Mask: A Look at the Process by Which Authentic Leaders Impact Follower Attitudes and Behaviors. The Leadership Quarterly, (15), 801-823.

Baltes, P. B. \& Kunzmann, U. (2003). Wisdom. The Psychologist, (16), 131-133.

Baltes, P. B. \& Kunzmann, U. (2004). The Two Faces of Wisdom: Wisdom as a General Theory of Knowledge and Judgment about Excellence in Mind and Virtue vs. Wisdom as Everyday Realization in People and Products. Human Development, 47, 290-299.

Baltes, P. B. \& Smith, J. (1990). Toward a Psychology of Wisdom and its Ontogenesis. In R. J. Sternberg (Ed.), Wisdom, Its Nature, Origins and Development. Cambridge: University Press.

Baltes, P. B. \& Staudinger, U. M. (2000). Wisdom: A Metaheuristic (pragmatic) to Orchestrate Mine and Virtue Towards Excellence. American Psychologist, 55, 122-136.

Baltes, P. B. (2004). Wisdom as Orchestration of Mind and Virtue. Manuscript in Preparation. Retrieved from http://library.mpib-berlin.mpg.de/ft/pb/ PB_Wisdom_2004.pdf

Baltes, P. B., Glück, J. \& Kunzmann, U. (2002). Wisdom: Its Structure and Function in Regulating Successful Lifespan Development. In C. R. Snyder and S. J. Lopez (Eds.), Handbook of positive psychology. London, England: Oxford University Press.

Bandura, A. (2003). On the Psychosocial Impact and Mechanisms of Spiritual Modeling. International Journal for the Psychology of Religion, 13(3), 167-17.

Bangen, K. J., Meeks, T. W. \& Jeste, D. V. (2013). Defining and Assessing Wisdom: A Review of the Literature. American Journal of Geriatric Psychiatry, 21(12), 1254- 1266.

Barry, H. ve Elovitz, P. (1992). Psychobiographical Explorations of Clinton and Perot. The Journal of Psvchohistory, 20 (2), 197-216. 
Birren, J. E. \& Fisher, L. M. (1990). The Elements of Wisdom: Overview and Integration. In R. J. Sternberg (Ed.), Wisdom, Its Nature, Origins and Development. Cambridge: Cambridge University Press.

Birren, J. E. \& Svensson, C. M. (2005). Wisdom in History. In R. Sternberg \& J. Jordan (Eds.), A Handbook of Wisdom: Psychological Perspectives. New York: Cambridge University Press.

Boal, K. B. \& Hooijberg, R. (2001). Strategic Leadership Research: Moving on. Leadership Quarterly, (11), 515-549.

Branson, C. M. (2009). Leadership for an Age of Wisdom. In Leadership for an Age of Wisdom (pp. 157-163). Dordrecht: Springer.

Buzzell, S., Boa, K., \& Perkins, B. (1998). The leadership bible. Grand Rapids, MI: Zondervan.

Chapa, O. \& Stringer, D. (2013). The Path of Measuring Moral Courage in the Workplace. SAM Advanced Management Journal, 78(2), 17-50.

Chrislip, D. D. \& Larson, C. E. (1994). Collaborative Leadership: How Citizens and Civic Leaders Can Make a Difference. San Francisco, CA: Jossey-Bass.

Courtney, J. F. (2001). Decision Making and Knowledge Management in İnquiring Organisations: Towards a New Decision-Making Paradigm for DSS. Decision Support Systems, (31), 17- 38 .

Dey, T. (2012). Wisdom and Leadership: A Conceptual Study on the Link Between the Two Literatures. The IUP Journal of Organizational Behavior, (11), 64-75.

Fairholm, M. R. (2004). Different Perspectives on the Practice of Leadership. Public Administration Review, (64), 577-590.

Ford, D. (2007). Christian Wisdom: Desiring God and Learning in Love. New York, NY: Cambridge University Press.

García-Marzá, D. (2005). Trust and Dialogue: Theoretical Approaches to Ethics Auditing. Journal of Business Ethics, 57(3), 209-219.

Govindji, R. (2015). The Role of Wisdom in Organisational Leadership, Doctoral Dissertation, Birmingham: Aston University.

Hays, J. M. (2007). Dynamics of Organizational Wisdom. Business Renaissance Quarterly, 2(4), 77-122.

Howard, L. W., Tang, T. L.P., \& Austin, M. J. (2015). Teaching Critical Thinking Skills: Ability, Motivation, Intervention, and the Pygmalion Effect. Journal of Business Ethics, 128(1), 133-147.

Jeste, D. V., Ardelt, M., Blazer, D., Kraemer, H. C., Vaillant, G., \& Meeks, T. W. (2010). Expert Consensus on Characteristics of Wisdom: A Delphi Method Study. The Gerontologist, (9), 1-13.

Kaygısız, E. G. (2013).Örgütsel Bilgeliğin Yaratılmasında Dönüşümsel Liderliğin Rolü Üzerine Bir Çalışma. Yayınlanmamış doktora tezi. Selçuk Üniversitesi, Konya. 
Knowles, M. S., Holton, E. F. \& Swanson, R. A. (2005). The Adult Learner: The Definitive Classic in Adult Education and Human Resource Development. Burlington, MA: Elsevier.

Kolb, D. A. (1984). Experiential learning: Experience as the Source of Learning and Development. Englewood Cliffs, NJ: Prentice-Hall.

Korac-Kakabadse, N., Korac-Kakabadse, A. \& Kouzim, A. (2001). Leadership Renewal: Towards the Philosophy of Wisdom. International Review of Administrative Sciences, (67), 207-227.

Kouzes, J. M. \& Posner, B. Z. (2007). The Leadership Challenge. San Francisco, CA: JosseyBass.

Livingston, S. R. (2012). Perceptions of Executive Coaches about Wisdom in Organizational Leaders. Doctoral dissertation, Indiana Wesleyan University.

Ludden, V. (2013). Wisdom Model for Leaders. Unpublished Manuscript, Department of Organizational Leadership, Marion: Indiana Wesleyan University.

McKenna, B., Rooney, D. \& Boal, K. B. (2009). Wisdom Principles as a Meta-Theoretical Basis for Evaluating Leadership. The Leadership Quarterly, (20), 177-190.

McKenna, B., Rooney, D., \& Kenworthy, A. L. (2013). Introduction: Wisdom and Aanagement-A Guest-Edited Special Collection of Resource Reviews For Management Educators. Academy of Management Learning and Education, 12(2), 306-311.

Meacham, J. A. (1990). The Loss of Wisdom. In R. J. Sternberg (Ed.), Wisdom: Its Nature, Origins and Development. Cambridge, England: Cambridge University Press.

Meeks, T. W. \& Jeste, D. V. (2009). Neurobiology of Wisdom: An Overview. Archives of General Psychiatry, 66, 355-365.

Merriam, S. B., Caffarella, R. S. \& Baumgartner, L. M. (2007). Learning in Adulthood: A Comprehensive Guide (3rd ed.). San Francisco, CA: John Wiley \& Sons.

Moberg, D. J. (2007). Practical Wisdom And Business Ethics: Presidential Address To The Society For Business Ethics Atlanta. Business Ethics Quarterly, 17(3), 535-561.

Morse, M. (1996). The Relationship of Wisdom to Transformational Leadership: Illustrated by the Historical Jesus. Faculty Publications - George Fox Evangelical Seminary

Nonaka, I. \& Takeuchi, H. (2011). The Big Idea: The Wise Leader. Harvard Business Review, 89, 58-67.

Önal, M. (2007), İslam Düşüncesinde 'Hikmet' Kavramları. FLSF (Felsefe ve Sosyal Bilimler Dergisi), (4), 113-122.

Pierre, J. C. (2016). The Influence of Ancient Chinese Wisdom on The Conceptualization and Practice of Leadership in Mainland China. Doctoral dissertation, California: Saybrook University.

Rooney, D. \& McKenna, B. (2008). Wisdom in Public Administration: Looking for a Sociology of Wise Practice. Public Administration Review, 709-721. 
Schulenburg, C. A. (2017). Perceptions of Wisdom by Organizational Leaders. Indiana: Wesleyan University.

Sternberg, R. J. (1990). Wisdom-Its Nature, Origins and Development, Cambridge: Cambridge University Press.

Sternberg, R. J. (1998). A Balance Theory of Wisdom. Review of General Psychology, 2, 347365.

Takahashi, M. \& Bordia, P. (2000). The Concept of Wisdom: A Cross-Cultural Comparison. International Journal of Psychology, 35(1), 1-9.

Takahashi, M. (2000). Toward a Culturally Inclusive Understanding of Wisdom: Historical Roots in the East and West. The International Journal of Aging and Human Development, 51(3), 217-230.

Trowbridge, R. H. (2006). The Scientific Approach of Wisdom. Doctoral Dissertation. Retrieved from ProQuest Dissertations ve Theses database. (UMI No. 3221771).

Trowbridge, R. H., \& Ferrari, M. (2011). Sophia and Phronesis in Psychology, Philosophy, and Traditional Wisdom. Research in Human Development, 8(2), 89-94.

Vera, D. \& Rodriguez-Lopez, A. (2004). Strategic Virtues: Humility as a Source of Competitive Advantage. Organizational Dynamics, 33, 393-408.

Walumbwa, F., Wang, P., Wang, H., Schaubroeck, J. \& Avolio, B. (2010). Psychological Processes Linking Authentic Leadership to Follower Behaviors. The Leadership Quarterly, 21, 901-914.

Weick, K. E. \& Ashford, S. J. (2000). Learning in Organizations. In F. M. Jablin ve L. L. Putnam (Eds.), The New Handbook of Organizational Communication: Advances in Theory, Research, and Methods Thousand Oaks, CA: SAGE.

Winter, D. G. (1991). A Motivational Model of Leadership: Predicting Long-Term Management Success from TAT Measures of Power Motivation and Responsibility. The Leadership Quarterly, 2, 67-80. 